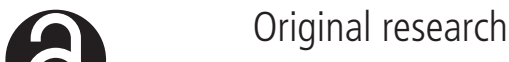

\section{Environmental exposures contribute to respiratory and allergic symptoms among women living in the banana growing regions of Costa Rica}

\author{
Brooke Alhanti (D) , ${ }^{1,2}$ Berna van Wendel de Joode (D) , Manuel Soto Martinez (D) , \\ Ana M Mora (D) , ${ }^{3,5}$ Leonel Córdoba Gamboa, ${ }^{3}$ Brian Reich, ${ }^{2,6}$ Christian H Lindh (D) , \\ Marcela Quirós Lépiz, ${ }^{3}$ Jane A Hoppin (10) 2,8
}

\begin{abstract}
- Additional supplemental material is published online only. To view, please visit the journal online (http://dx.doi. org/10.1136/oemed-2021 107611)
\end{abstract}

For numbered affiliations see end of article.

Correspondence to Dr Jane A Hoppin, Center for Human Health and the Environment, North Carolina State University, Raleigh, North Carolina, USA; jahoppin@ncsu.edu

Received 4 May 2021 Accepted 9 December 2021

Check for updates

(c) Author(s) (or their employer(s)) 2021. Re-use permitted under CC BY-NC. No commercial re-use. See rights and permissions. Published by BMJ.

To cite: Alhanti $B$, van Wendel de Joode B,

Soto Martinez $\mathrm{M}$, et al.

Occup Environ Med Epub

ahead of print: [please include

Day Month Year].doi:10.1136/ oemed-2021-107611

\section{ABSTRACT}

Objectives This research evaluates whether environmental exposures (pesticides and smoke) influence respiratory and allergic outcomes in women living in a tropical, agricultural environment.

Methods We used data from 266 mothers from the Infants' Environmental Health cohort study in Costa Rica. We evaluated environmental exposures in women by measuring seven pesticide and two polycyclic aromatic hydrocarbons metabolites in urine samples. We defined 'high exposure' as having a metabolite value in the top 75th percentile. We collected survey data on respiratory and allergic outcomes in mothers as well as on pesticides and other environmental exposures. Using logistic regression models adjusted for obesity, we assessed the associations of pesticide exposure with multiple outcomes (wheeze, doctor-diagnosed asthma, high ( $\geq 2$ ) asthma score based on symptoms, rhinitis, eczema and itchy rash).

Results Current pesticide use in the home was positively associated with diagnosed asthma $(O R=1.99$ ( $95 \% \mathrm{Cl}=1.05$ to 3.87$))$. High urinary levels of 5-hydroxythiabendazole (thiabendazole metabolite) and living in a neighbourhood with frequent smoke from waste burning were associated with a high asthma score $(O R=1.84(95 \% \mathrm{Cl}=1.05$ to 3.25$)$ and $\mathrm{OR}=2.31(95 \% \mathrm{Cl}=1.11$ to 5.16$)$, respectively). Women who worked in agriculture had a significantly lower prevalence of rhinitis $(0.19$ (0.01 to 0.93$))$, but were more likely to report eczema $(\mathrm{OR}=2.54(95 \% \mathrm{Cl}=1.33$ to 4.89$))$ and an itchy rash $(\mathrm{OR}=3.17(95 \% \mathrm{Cl}=1.24$ to 7.73)).

Conclusions While limited by sample size, these findings suggest that environmental exposure to both pesticides and smoke may impact respiratory and skinrelated allergic outcomes in women.

\section{INTRODUCTION}

Women living in rural settings in low/middleincome countries experience a myriad of environmental exposures that can cause or exacerbate respiratory and allergic diseases. These environmental exposures can occur around the home as well as in the community or workplace. Women living in the banana growing regions in Costa Rica are exposed to a variety of environmental exposures such as pesticides, including fungicides (eg,

\section{Key messages}

What is already known about this subject?

- Pesticides may contribute to respiratory and allergic symptoms in occupationally exposed individuals. A majority of these studies have been conducted in men.

What are the new findings?

- Specific pesticides were associated with increased asthma symptoms in environmentally exposed women in Costa Rica.

- Occupationally exposed women were more likely to report allergic skin conditions than respiratory allergic conditions.

- Waste burning in rural settings continues to be a risk for asthma symptoms.

How might this impact on policy or clinical practice in the foreseeable future?

- These results may support stronger pesticide use controls which minimise environmental and occupational exposure. Waste burning should be replaced with more health protective means of waste disposal.

mancozeb), insecticides (eg, chlorpyrifos, permethrin, buprofezin) and herbicides (eg, 2,4-D), and smoke from various sources. ${ }^{1-5}$ Pesticide exposures occur through multiple pathways, including ambient exposure via aerial spraying, direct contact via occupational exposure and para-occupational exposure due to other household members working in agriculture. ${ }^{16}$ Pesticides are also applied in/ around the home by the Ministry of Health or women themselves, mainly for vector control. Exposures to smoke can be caused by tobacco smoke, household and industrial waste burning, or use of biomass for cooking fuel. ${ }^{45}$

Both pesticide and smoke exposures have been related to respiratory and allergic outcomes in women globally. Pesticides have been associated with respiratory and allergic symptoms in occupationally exposed populations. ${ }^{17-9}$ Studies investigating the relationships between agricultural pesticide exposure and health outcomes have traditionally focused on men, but are increasingly examining women as many women are employed 
in agriculture. ${ }^{18-12}$ Previous research on women exposed to pesticides has found increased risk of respiratory and allergic outcomes like rhinitis. ${ }^{9} 1113$ Allergic skin conditions may also be associated with pesticide exposure, ${ }^{14-16}$ but more research on this relationship in women is warranted. Smoke exposure from waste burning (both commercial and household) and the use of biomass cooking fuel has been associated with respiratory symptoms and allergic symptoms such as rhinitis in resource-poor countries. $^{17-20}$

The Infants' Environmental Health ('Infantes y Salud Ambiental', ISA) study is a prospective birth cohort study of pregnant women and their children living near banana plantations in Matina County, Costa Rica. ${ }^{21}$ This analysis examines the associations of women's exposure to pesticides (during pregnancy and when their children were 1 and 5 years old) and smoke (when their children were 5 years old) with respiratory and allergic outcomes. The goal of this study is to observe the relationship between these environmental exposures and the health of women in a resource-poor setting. We hypothesised that higher exposures to both pesticides and smoke would be associated with a higher likelihood of respiratory and allergic symptoms.

\section{METHODS}

\section{Study design}

The ISA study enrolled 451 pregnant women between March 2010 and June 2011. ${ }^{21}$ Eligible women were age $>15$ years, $<33$ weeks pregnant and lived in Matina County, Costa Rica. Women completed 2-6 study visits between pregnancy and when their children were 5 years old. These were 1-3 study visits during pregnancy (depending on their gestational age at enrollment), shortly after delivery (median $=7$ weeks postpartum) and when their children were 1 and 5 years old (online supplemental figure S1). The majority of the attrition in the cohort occurred soon after childbirth.

This analysis focuses the 290 women who completed a questionnaire when their children were 5 years old (figure 1). We excluded the 24 women with any history of smoking, resulting in an effective sample size of 266 . Only 259 women provided a urine sample at their children's 5 -year study visit.

Women completed a questionnaire based on both previous ISA questionnaires and the European Community Respiratory Health Survey at their children's 5-year study visit that collected information on age, education, parity, smoking history, occupational history and medical history (eg, medical conditions and medication use). ${ }^{22}$ We also asked women about environmental exposures such as residential pesticide use, vector-control pesticide spraying by health

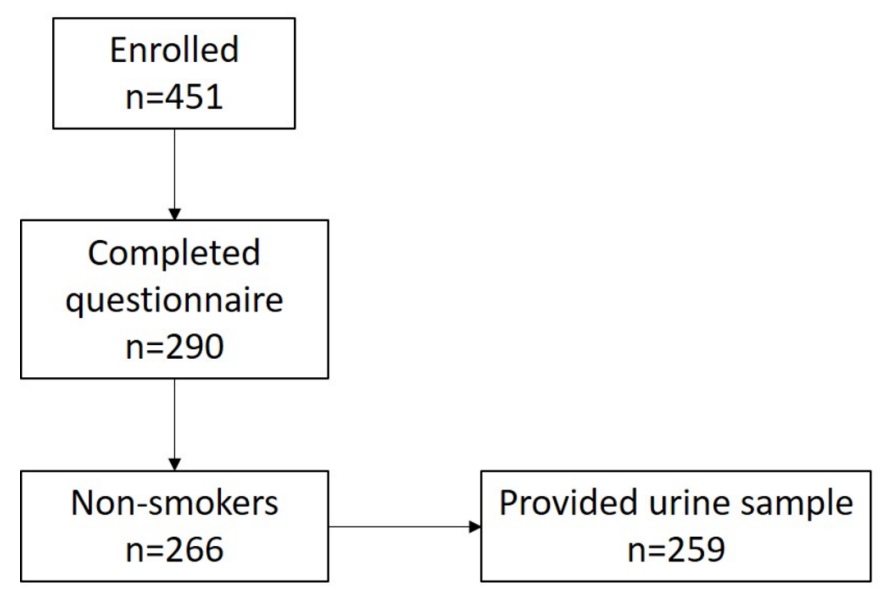

Figure 1 Cohort sample sizes, Matina County, Costa Rica, 2010-2017. authorities, frequency of smoke from any waste burning, cooking fuel use and tobacco use (both personally and in their homes). This questionnaire has been previously used in studies of Costa Rican populations. ${ }^{12324}$ Women's height and weight were measured at the same study visit and used to calculate body mass index (BMI).

All mothers provided written informed consent at enrollment and additional informed consent was obtained from the parents or legal guardians of participants aged $<18$ years.

\section{Respiratory and allergic outcomes}

We examined three respiratory outcomes: (1) wheeze, (2) doctor-diagnosed asthma and (3) asthma symptom score based on Sunyer's methodology (a score ranging from 0 to 5 based on the following symptoms: wheezing with shortness of breath in the last 12 months, woken up with a feeling of chest tightness in the last 12 months, attack of shortness of breath at rest in the last 12 months, attack of shortness of breath after exercise in the last 12 months and woken by attack of shortness of breath in the last 12 months). ${ }^{25}$ The asthma score was developed using baseline self-reported responses from the health survey and has shown to be predictive of future asthma medication use and airway reactivity follow-up. ${ }^{26}$ We chose this as a potential metric of undiagnosed or poorly managed asthma in this medically underserved community. For our statistical analysis, we a priori dichotomised the asthma scores into low (0-1) and high $(2-5)$.

We considered rhinitis, eczema and itchy rash as allergic outcomes. We recognise that these may not all meet the definition of allergy as defined by specific or total IgE. ${ }^{27}$ Notably, the questions related to eczema and itchy rash were administered to all $(n=266)$, whereas the rhinitis question was administered to only 246 women (it was added to the questionnaire after the study visits had started).

\section{Exposure assessment of pesticides and markers of smoke}

At each study visit, we collected spot urine samples, which were frozen and shipped on dry ice to the lab. Details of specimen collection and analysis have been previously published. ${ }^{21}$ Urine samples were analysed at the Department of Occupational and Environmental Medicine at Lund University in Sweden. The laboratory participates and has qualified as a European Human Biomonitoring Initiative (HBM4EU) laboratory for the analysis of 1-hydroxypyrene (1-HP). Urinary metabolites were measured using liquid chromatography coupled to tandem mass spectrometry (QTRAP 5500, AB Sciex, Framingham, Massachusetts, USA). Briefly, the samples were analysed for fungicides (ethylenethiourea (ETU, metabolite of mancozeb), hydroxypyrimethanil (OHP, metabolite of pyrimethanil), 5-hydroxythiabendazole (OHT, metabolite of thiabendazole)), organophosphate (OP) insecticides (3,5,6-trichloro-2-pyridinol (TCP, metabolite of chlorpyrifos) used in banana plantations, the sum of cis/trans (3-(2,2-dichlorovinyl)-2,2-dimethylcyclopropaneca rboxylic acid (DCCA, metabolite of permethrin, cypermethrin and cyfluthrin)), 3-phenoxybenzoic acid (3PBA, metabolite of permethrin, cypermethrin, cyfluthrin, deltamethrin, allethrin, resmethrin and fenvalerate)) and the herbicide 2,4-D. ${ }^{28}$ Urine samples collected from women when their children were 5 years old were also analysed for 1-HP and hydroxyphenanthrene (2-OH-PH), biomarkers of exposure to polycyclic aromatic hydrocarbons (PAHs) which can originate from wood burning. ${ }^{29} 30$ Urinary metabolite concentrations were corrected for dilution using specific gravity. Detection limits have been previously published. ${ }^{21} 2830$ Metabolite concentrations below the limit of detection (LOD) were randomly imputed to vary between half the LOD and the LOD. 


\section{Statistical analysis}

Sociodemographic, outcome and exposure data were summarised with counts (\%) for categorical variables and medians (25th, 75 th percentiles) for continuous variables. Frequency of smoke from waste burning was grouped into three categories: Never, Some/Monthly and Weekly/Daily. The association between a woman working in agriculture and having high levels of OHT was assessed with a $\chi^{2}$ test. Spearman correlation coefficients between metabolites were calculated.

Women's pesticide exposures were classified as 'historic' (ie, during pregnancy, shortly after delivery and when their children were 1 year old) or 'current' (ie, when their children were 5 years old). Due to the large variability in metabolite concentrations and presence of extreme values, we dichotomised current exposure to each pesticide or PAHs biomarker into low ( $\leq 75$ th percentile) and high ( $>75$ th percentile). This was done prior to any modelling analysis. The cut point was selected based on the distributions of the metabolites in conjunction with power considerations (online supplemental figure S2). Historic pesticide exposures also varied widely over time, thus we used the overall historic distributions to identify a cut point for 'high' exposure..$^{21}$ To avoid regression to the mean in the historic exposures, we created distributions of pesticide exposures from all historic samples. A woman who exceeded the 75th percentile of a distribution in more than $40 \%$ of her historic study visits was considered to have frequent high exposure to that pesticide. Frequent high exposure was defined as greater than $40 \%$ of a woman's historic visits based on the number of visits where exposures were high ( $>75$ th percentile). This method of exposure classification was driven by the short half-lives of pesticide metabolites and assumes if a woman has been frequently exposed to high levels of a specific pesticide she is likely to have repeated exposure to this pesticide.

We fit individual logistic regression models adjusted for obesity (dichotomous: BMI $<30, \mathrm{BMI} \geq 30$ ) to assess the exposure-outcome associations of interest. We excluded ever smokers $(n=24)$ from our main models, but they were included in sensitivity analyses. We highlight statistically significant associations $(\alpha=0.05)$. All analyses were done in R (V.3.6.1). ${ }^{31}$

\section{RESULTS}

A total of 266 women were included in this analysis. At the time of questionnaire administration (2016-2017), the median (25th, 75 th) age of study participants was $29(25,35)$ years and $45 \%$ $(n=119)$ of the women were obese (table 1). Women included in our main analysis did not smoke or live with someone who frequently smoked.

Doctor-diagnosed asthma was more commonly reported $(21 \%, \mathrm{n}=56)$ than wheeze in the 12 months prior to the survey $(16 \%, n=43$; table 1$)$. The asthma score was right skewed with $44 \%(n=118)$ of participants having a score of 0 . A total of 98 women (37\%) had two or more asthma symptoms and were considered to have a high asthma score. About $70 \%(n=184)$ of the women with a high asthma score had been diagnosed with asthma by a doctor, whereas $8 \%(n=20)$ reported an asthma diagnosis but did not have a high asthma score (table 2). The variability between diagnosed asthma and symptomatic asthma suggests some women with asthmatic symptoms were not diagnosed with asthma, while others had well-controlled asthma as they were asymptomatic.

We evaluated three allergic outcomes (rhinitis, itchy rash and eczema). Rhinitis $(9 \%, \mathrm{n}=25)$ and itchy rash $(9 \%, \mathrm{n}=25)$ were uncommon, but eczema $(31 \%, \mathrm{n}=83)$ was reported by about one-third of the study population (table 1).
Table 1 Demographic, health and exposure data for 266 nonsmoking women living in Matina County, Costa Rica, 2016-2017

\begin{tabular}{|c|c|c|}
\hline & Median & (25th, 75th) \\
\hline \multicolumn{3}{|l|}{ Cohort demographics } \\
\hline \multirow[t]{2}{*}{ Age } & 29 & $(25,35)$ \\
\hline & $\mathbf{n}$ & $\%$ \\
\hline \multicolumn{3}{|l|}{ Obesity } \\
\hline Obese $(\mathrm{BMI}>30)$ & 119 & 44.7 \\
\hline Not obese (BMI <30) & 147 & 55.3 \\
\hline \multicolumn{3}{|l|}{ Outcomes } \\
\hline Wheeze & 43 & 16.2 \\
\hline Asthma diagnosed by doctor & 56 & 21.1 \\
\hline \multicolumn{3}{|l|}{ Asthma score ${ }^{25}$} \\
\hline 0 & 118 & 44.4 \\
\hline 1 & 50 & 18.8 \\
\hline 2 & 34 & 12.8 \\
\hline 3 & 27 & 10.2 \\
\hline 4 & 24 & 9.0 \\
\hline 5 & 13 & 4.9 \\
\hline \multicolumn{3}{|l|}{ Dichotomised asthma score } \\
\hline 0,1 & 168 & 63.2 \\
\hline $2,3,4,5$ & 98 & 36.8 \\
\hline Rhinitis & 25 & 9.4 \\
\hline Missing* & 17 & 6.4 \\
\hline Eczema & 83 & 31.2 \\
\hline Itchy rash & 25 & 9.4 \\
\hline \multicolumn{3}{|l|}{ Exposures } \\
\hline Historic urine sample obtained & 266 & 100 \\
\hline Concurrent urine sample obtained & 259 & 97.4 \\
\hline Missing & 9 & 3.1 \\
\hline $\begin{array}{l}\text { Mother worked in banana or other agriculture business in the } \\
\text { last } 3 \text { years }\end{array}$ & 89 & 33.5 \\
\hline Missing & 9 & 3.4 \\
\hline $\begin{array}{l}\text { Mother currently working in banana or other agriculture } \\
\text { business }\end{array}$ & 47 & 17.7 \\
\hline Missing & 9 & 3.4 \\
\hline Husband worked in banana field in the last 3 years & 137 & 51.5 \\
\hline Missing & 9 & 3.4 \\
\hline Husband currently working in banana field & 125 & 47 \\
\hline Missing & 9 & 3.4 \\
\hline $\begin{array}{l}\text { Husband worked in other agriculture business in the last } 3 \\
\text { years }\end{array}$ & 21 & 7.9 \\
\hline Missing & 9 & 3.4 \\
\hline Husband currently working in other agriculture business & 14 & 5.3 \\
\hline Missing & 9 & 3.4 \\
\hline \multicolumn{3}{|l|}{ Smoke from waste burning reached house (grouped) } \\
\hline Never & 44 & 16.5 \\
\hline Some/monthly & 54 & 20.3 \\
\hline Weekly/daily & 168 & 63.2 \\
\hline Cooking fuel: gas & 235 & 88.3 \\
\hline Cooking fuel: wood & 66 & 24.8 \\
\hline Cooking fuel: electric & 50 & 18.8 \\
\hline Pesticide used inside the home & 139 & 52.3 \\
\hline Missing & 11 & 4.1 \\
\hline Pesticide used outside the home & 13 & 4.9 \\
\hline Missing & 14 & 5.3 \\
\hline Vector control (spraying by health authorities) & 146 & 54.9 \\
\hline Missing & 11 & 4.1 \\
\hline
\end{tabular}

${ }^{*} \mathrm{n}=17$ women received a questionnaire missing a question about rhinitis.

BMI, body mass index.

We also collected data on non-specific occupational and residential exposures using self-reported information (table 1). One-third of study participants reported working in agriculture (including banana farms) in the 3 years prior to the health survey $(34 \%, n=89)$. About half of the women reported using pesticides 
Table 2 Diagnosed asthma and asthma score counts for 266 nonsmoking women living in Matina County, Costa Rica, 2016-2017

\begin{tabular}{lrrrrrr}
\hline & \multicolumn{7}{l}{ Asthma score } \\
\cline { 2 - 7 } Diagnosed asthma & $\mathbf{0}$ & $\mathbf{1}$ & $\mathbf{2}$ & $\mathbf{3}$ & $\mathbf{4}$ & $\mathbf{5}$ \\
\hline Yes & 12 & 8 & 8 & 12 & 11 & 5 \\
No & 106 & 42 & 26 & 15 & 13 & 8 \\
\hline
\end{tabular}

inside their home $(52 \%, \mathrm{n}=139)$ or having been exposed to vector-control pesticide spraying by health authorities during the last 6 months $(55 \%, n=146)$. Waste burning was common with most women reporting smoke from waste burning reaching their home daily or weekly $(63 \%, \mathrm{n}=168)$.

Pesticide exposure was common in the study population; over 99\% of historic samples had detectable concentrations of all metabolites. Detection in current samples was also high (pyrethroids, ETU, TCP and 2,4-D were detected in all samples). OHP was measured in $92 \%$ of current samples; OHT was measured in $72 \%$ of samples (online supplemental table S1). The range of each metabolite as well as the value used for the 75 th percentile cutoff is shown in online supplemental table S1. Historic pesticide exposure levels were similar to current exposure concentrations for TCP, 2,4-D, OHP and OHT. For ETU, current exposures were slightly lower than historic exposures. Pyrethroid (3PBA,
DCCA and combined pyrethroids) concentrations were slightly higher in current samples. Women who worked in agriculture were more likely to have high values of OHT $(p<0.001)$. Metabolites of PAHs were detected in 94\% (2-OH-PH) and 98\% (1-HP) of the current samples. PAH metabolites were correlated with each other $(r=0.74)$, but most pesticide metabolites had weak correlations (online supplemental table S2). Only 3PBA and DCCA were strongly correlated, as they are both markers of pyrethroids $(\mathrm{r}=0.80)$. Respiratory outcomes were associated with self-reported exposure to pesticides and other environmental chemicals and with current urinary pesticide metabolite concentrations, but there was no clear pattern in the results (table 3). Pesticide use in the home was associated with increased odds of doctor-diagnosed asthma $(\mathrm{OR}=1.99,95 \% \mathrm{CI}$ : $(1.05$ to $3.87)$ ). For the symptom-based asthma score, frequent exposure to smoke burning (daily/weekly vs never) was significantly associated with a high asthma score $(\mathrm{OR}=2.31,95 \% \mathrm{CI}$ : $(1.11$ to 5.16)). Wheeze was not associated with any occupational or residential exposures assessed via questionnaire. Current high OHT exposure was associated with a high asthma score $(\mathrm{OR}=1.84$, 95\% CI: (1.05 to 3.25$)$ ). Wheeze was inversely associated with high historic pyrethroid exposure (OR $=0.38,95 \% \mathrm{CI}$ : $(0.14$ to $0.91)$ ) and DCCA (OR $=0.31,95 \% \mathrm{CI}$ : (0.10 to 0.77$)$ (online supplemental table S3); current exposures showed similar associations (table 3). Doctor-diagnosed asthma had a suggestive

Table 3 Unadjusted ORs and adjusted ORs (aORs) for respiratory outcomes and environmental exposures in non-smoking women living in Matina County, Costa Rica, 2016-2017 ( $n=266)$

\begin{tabular}{|c|c|c|c|c|c|c|c|}
\hline \multirow{2}{*}{ Exposure } & \multirow[b]{2}{*}{$\mathrm{n}$ exposed } & \multicolumn{2}{|l|}{ Wheeze $(n=43)$} & \multicolumn{2}{|c|}{ Doctor-diagnosed asthma $(n=56)$} & \multicolumn{2}{|c|}{ High asthma score $(n=98)$} \\
\hline & & OR $(95 \% \mathrm{Cl})$ & $\mathrm{aOR}^{*}(95 \% \mathrm{CI})$ & OR $(95 \% \mathrm{Cl})$ & $\mathrm{aOR}^{*}(95 \% \mathrm{Cl})$ & OR $(95 \% \mathrm{CI})$ & $\mathrm{aOR}^{*}(95 \% \mathrm{Cl})$ \\
\hline \multicolumn{8}{|c|}{ Occupational/residential exposures ( $n=266$ ) } \\
\hline $\begin{array}{l}\text { Mother currently works in } \\
\text { banana or other agriculture } \\
\text { business }\end{array}$ & 47 & $1.69(0.73$ to 3.67$)$ & $1.75(0.75$ to 3.89$)$ & $1.58(0.74$ to 3.20$)$ & $1.64(0.76$ to 3.40$)$ & $1.81(0.73$ to 4.22$)$ & $1.4(0.72$ to 2.70$)$ \\
\hline $\begin{array}{l}\text { Father currently works on } \\
\text { banana plantation }\end{array}$ & 125 & 0.79 (0.39 to 1.56$)$ & 0.68 (0.33 to 1.37$)$ & 0.89 (0.48 to 1.62$)$ & 0.77 (0.41 to 1.43$)$ & 1.04 (0.49 to 2.19$)$ & $1.21(0.72$ to 2.05$)$ \\
\hline $\begin{array}{l}\text { Father worked in other } \\
\text { agriculture business in last } \\
3 \text { years }\end{array}$ & 21 & $1.35(0.37$ to 3.91$)$ & $1.26(0.34$ to 3.71$)$ & $2.54(0.96$ to 6.40$)$ & $2.43(0.90$ to 6.28$)$ & $0.79(0.12$ to 3.07$)$ & $1.26(0.49$ to 3.14$)$ \\
\hline $\begin{array}{l}\text { Pesticide used inside the } \\
\text { home }\end{array}$ & 139 & 1.24 (0.62 to 2.51$)$ & 1.14 (0.57 to 2.34$)$ & 2.11 (1.13 to 4.08$)$ & 1.99 (1.05 to 3.87$)$ & 1.66 (0.78 to 3.68$)$ & $1.17(0.70$ to 1.99$)$ \\
\hline Government spraying & 146 & $1.23(0.62$ to 2.53$)$ & 1.35 (0.67 to 2.81$)$ & 1.44 (0.78 to 2.73$)$ & 1.59 (0.84 to 3.06$)$ & $0.89(0.42$ to 1.91$)$ & 0.91 (0.54 to 1.54$)$ \\
\hline \multicolumn{8}{|c|}{ Smoke from waste burning reached house } \\
\hline Never & 44 & Ref & Ref & Ref & Ref & Ref & Ref \\
\hline Some months/monthly & 54 & $1.36(0.42$ to 4.80$)$ & $1.32(0.40$ to 4.71$)$ & $1.15(0.42$ to 3.26$)$ & 1.11 (0.40 to 3.20$)$ & 1.02 (0.33 to 3.20$)$ & 1.35 (0.55 to 3.40$)$ \\
\hline Weekly/daily & 168 & $1.7(0.66$ to 5.23$)$ & $1.82(0.70$ to 5.67$)$ & $1.27(0.57$ to 3.15$)$ & 1.36 (0.60 to 3.42 ) & 1.06 (0.43 to 2.88$)$ & 2.31 (1.11 to 5.16$)$ \\
\hline \multicolumn{8}{|l|}{ Current metabolitest $(n=259)$} \\
\hline \multicolumn{8}{|l|}{ Pesticides } \\
\hline ETU & 70 & $1.1(0.51$ to 2.24$)$ & $1.07(0.50$ to 2.20$)$ & 1.03 (0.52 to 1.98$)$ & 1 (0.50 to 1.94$)$ & 0.73 (0.29 to 1.65$)$ & 0.84 (0.46 to 1.48$)$ \\
\hline $\mathrm{TCP}$ & 63 & 0.7 (0.29 to 1.53$)$ & 0.68 (0.28 to 1.51$)$ & 1.74 (0.89 to 3.30$)$ & 1.75 (0.89 to 3.36$)$ & 0.62 (0.22 to 1.50$)$ & 0.97 (0.53 to 1.75$)$ \\
\hline $2,4-D$ & 65 & $0.79(0.34$ to 1.69$)$ & $0.82(0.35$ to 1.76$)$ & 0.71 (0.33 to 1.42$)$ & $0.73(0.33$ to 1.48$)$ & $1.08(0.46$ to 2.35$)$ & $0.86(0.47$ to 1.56$)$ \\
\hline OHP & 66 & 0.65 (0.27 to 1.42$)$ & 0.67 (0.27 to 1.49$)$ & 0.6 (0.27 to 1.22$)$ & 0.62 (0.28 to 1.28$)$ & 1.7 (0.76 to 3.65$)$ & 1.57 (0.88 to 2.80$)$ \\
\hline OHT & 70 & 1.44 (0.69 to 2.88$)$ & $1.46(0.70$ to 2.96$)$ & 1.29 (0.66 to 2.44$)$ & $1.31(0.67$ to 2.51$)$ & $1.7(0.76$ to 3.65$)$ & $1.84(1.05$ to 3.25$)$ \\
\hline 3PBA & 65 & 0.79 (0.34 to 1.69$)$ & 0.7 (0.30 to 1.52$)$ & 1.64 (0.85 to 3.11$)$ & 1.5 (0.76 to 2.88$)$ & 1.06 (0.44 to 2.37$)$ & 1.1 (0.61 to 1.96$)$ \\
\hline DCCA & 65 & $0.55(0.22$ to 1.24$)$ & $0.53(0.20$ to 1.20$)$ & 0.71 (0.33 to 1.42$)$ & $0.67(0.31$ to 1.37$)$ & 0.91 (0.38 to 2.01$)$ & 0.74 (0.40 to 1.34$)$ \\
\hline Pyrethroid & 64 & $0.57(0.22$ to 1.27$)$ & $0.52(0.20$ to 1.19$)$ & $0.94(0.46$ to 1.85$)$ & $0.88(0.42$ to 1.75$)$ & $1(0.41$ to 2.21$)$ & 0.9 (0.49 to 1.62$)$ \\
\hline \multicolumn{8}{|c|}{ Polycyclic aromatic hydrocarbons } \\
\hline 1-HP & 71 & $0.68(0.29$ to 1.45$)$ & $0.6(0.25$ to 1.30$)$ & $0.96(0.48$ to 1.84$)$ & 0.86 (0.42 to 1.67$)$ & 1.05 (0.47 to 2.27$)$ & 0.69 (0.37 to 1.23$)$ \\
\hline 2-OH-HP & 62 & $0.84(0.36$ to 1.81$)$ & $0.6(0.25$ to 1.30$)$ & 1.08 (0.53 to 2.10$)$ & 1.02 (0.49 to 2.02$)$ & $1.22(0.52$ to 2.70$)$ & $0.96(0.52$ to 1.74$)$ \\
\hline
\end{tabular}

${ }^{*}$ ORs adjusted for obesity $(\mathrm{BMI} \geq 30)$

tDichotomised at the 75th percentile.

‡Sum of 3PBA and DCCA.

BMI, body mass index; DCCA, 3-(2,2-dichlorovinyl)-2,2-dimethylcyclopropanecarboxylic acid; ETU, ethylenethiourea; 1-HP, 1-hydroxypyrene; 2-OH-HP, hydroxyphenanthrene; OHP, hydroxypyrimethanil; OHT, 5-hydroxythiabendazole; 3PBA, 3-phenoxybenzoic acid; TCP, 3,5,6-trichloro-2-pyridinol. 
Table 4 Unadjusted ORs and adjusted ORs (aORs) between allergic outcomes and environmental exposures in non-smoking women living in Matina County, Costa Rica, 2016-2017 ( $\mathrm{n}=266)$

\begin{tabular}{|c|c|c|c|c|c|c|c|}
\hline \multirow[b]{2}{*}{ Exposure } & \multirow[b]{2}{*}{$\mathrm{n}$ exposed } & \multicolumn{2}{|l|}{ Rhinitis $(n=25)$} & \multicolumn{2}{|l|}{ Eczema $(n=83)$} & \multicolumn{2}{|l|}{ Itchy rash $(n=25)$} \\
\hline & & OR $(95 \% \mathrm{Cl})$ & $\mathrm{aOR} *(95 \% \mathrm{Cl})$ & OR $(95 \% \mathrm{Cl})$ & $\mathrm{aOR} *(95 \% \mathrm{Cl})$ & OR $(95 \% \mathrm{Cl})$ & $\mathrm{aOR} *(95 \% \mathrm{Cl})$ \\
\hline \multicolumn{8}{|c|}{ Occupational/residential exposures $(n=266)$} \\
\hline $\begin{array}{l}\text { Mother currently works in } \\
\text { banana or other agriculture } \\
\text { business }\end{array}$ & 47 & $0.19(0.01$ to 0.94$)$ & 0.19 (0.01 to 0.93$)$ & 2.51 (1.31 to 4.81$)$ & 2.54 (1.33 to 4.89$)$ & 3.08 (1.22 to 7.45$)$ & $3.17(1.24$ to 7.73$)$ \\
\hline $\begin{array}{l}\text { Father currently works on } \\
\text { banana plantation }\end{array}$ & 125 & 0.2 (0.06 to 0.54$)$ & 0.2 (0.06 to 0.56$)$ & 1.12 (0.66 to 1.90$)$ & 1.08 (0.63 to 1.84$)$ & 0.88 (0.37 to 2.05$)$ & $0.81(0.34$ to 1.90$)$ \\
\hline $\begin{array}{l}\text { Father worked in other } \\
\text { agriculture business in last } \\
3 \text { years }\end{array}$ & 21 & $1.02(0.15$ to 3.85$)$ & 1.04 (0.16 to 3.94$)$ & 1.37 (0.52 to 3.41$)$ & 1.34 (0.51 to 3.33$)$ & 3.57 (1.08 to 10.30$)$ & $3.44(1.03$ to 10.00$)$ \\
\hline $\begin{array}{l}\text { Pesticide used inside the } \\
\text { home }\end{array}$ & 139 & 1.34 (0.56 to 3.35$)$ & $1.36(0.57$ to 3.40$)$ & 1.03 (0.61 to 1.76$)$ & $1(0.59$ to 1.71$)$ & 1.33 (0.56 to 3.31$)$ & $1.25(0.52$ to 3.13$)$ \\
\hline Government spraying & 146 & 2.47 (0.99 to 7.03$)$ & 2.43 (0.97 to 6.93$)$ & 0.94 (0.55 to 1.61$)$ & 0.96 (0.56 to 1.65$)$ & $0.66(0.28$ to 1.56$)$ & $0.69(0.29$ to 1.64$)$ \\
\hline \multicolumn{8}{|c|}{ Smoke from waste burning reached house } \\
\hline Never & 44 & Ref & Ref & Ref & Ref & Ref & Ref \\
\hline Some months/monthly & 54 & $2.49(0.54$ to 17.65$)$ & $2.55(0.55$ to 18.15$)$ & 1.19 (0.51 to 2.86$)$ & 1.18 (0.50 to 2.83$)$ & 1.44 (0.49 to 4.57$)$ & 1.41 (0.47 to 4.51$)$ \\
\hline Weekly/daily & 168 & $2.4(0.65$ to 15.56$)$ & 2.38 (0.64 to 15.43$)$ & 1.07 (0.53 to 2.27$)$ & 1.09 (0.53 to 2.31$)$ & $0.36(0.12$ to 1.13$)$ & $0.37(0.12$ to 1.16$)$ \\
\hline \multicolumn{8}{|l|}{ Current metabolitest $(n=259)$} \\
\hline \multicolumn{8}{|l|}{ Pesticides } \\
\hline ETU & 70 & 0.83 (0.29 to 2.05$)$ & 0.83 (0.29 to 2.08$)$ & 0.93 (0.50 to 1.66$)$ & 0.92 (0.50 to 1.65$)$ & $1.1(0.41$ to 2.65$)$ & 1.08 (0.40 to 2.61$)$ \\
\hline TCP & 63 & $1.91(0.77$ to 4.50$)$ & $1.93(0.77$ to 4.55$)$ & $1.14(0.61$ to 2.06$)$ & 1.13 (0.61 to 2.06$)$ & $0.59(0.171 .62)$ & $0.58(0.16$ to 1.60$)$ \\
\hline 2,4-D & 65 & $0.38(0.09$ to 1.15$)$ & $0.38(0.09$ to 1.14$)$ & $1.17(0.64$ to 2.11$)$ & $1.19(0.65$ to 2.15$)$ & 0.97 (0.34 to 2.43$)$ & $1(0.35$ to 2.51$)$ \\
\hline $\mathrm{OHP}$ & 66 & $1.19(0.44$ to 2.90$)$ & $1.18(0.44$ to 2.87$)$ & 1.14 (0.62 to 2.05$)$ & 1.16 (0.63 to 2.08$)$ & 0.55 (0.16 to 1.51$)$ & 0.57 (0.16 to 1.57$)$ \\
\hline OHT & 70 & $0.39(0.09$ to 1.18$)$ & $0.38(0.09$ to 1.16$)$ & 1.71 (0.96 to 3.02$)$ & 1.72 (0.96 to 3.04$)$ & 2.01 (0.83 to 4.67$)$ & 2.04 (0.84 to 4.76$)$ \\
\hline 3PBA & 65 & $1.86(0.75$ to 4.38$)$ & 1.96 (0.78 to 4.66$)$ & 1.07 (0.58 to 1.93$)$ & 1.04 (0.56 to 1.88$)$ & 1.23 (0.46 to 2.97$)$ & 1.13 (0.42 to 2.77$)$ \\
\hline DCCA & 65 & $1.77(0.71$ to 4.16$)$ & $1.81(0.73$ to 4.28$)$ & $0.88(0.47$ to 1.61$)$ & $0.87(0.47$ to 1.60$)$ & 1.52 (0.59 to 3.61$)$ & $1.49(0.58$ to 3.55$)$ \\
\hline Pyrethroid $\neq$ & 64 & $1.56(0.61$ to 3.72$)$ & $1.6(0.62$ to 3.83$)$ & 1.33 (0.73 to 2.39$)$ & 1.31 (0.71 to 2.35$)$ & 1.55 (0.61 to 3.69$)$ & 1.49 (0.58 to 3.56$)$ \\
\hline \multicolumn{8}{|c|}{ Polycyclic aromatic hydrocarbons } \\
\hline 1-HP & 71 & $0.86(0.30$ to 2.15$)$ & $0.88(0.31$ to 2.22$)$ & $1.28(0.71$ to 2.27$)$ & 1.24 (0.69 to 2.21$)$ & 1.28 (0.50 to 3.02$)$ & 1.18 (0.46 to 2.83$)$ \\
\hline 2-OH-PH & 62 & $0.59(0.17$ to 1.65$)$ & $0.6(0.17$ to 1.67$)$ & $1.06(0.57$ to 1.94$)$ & 1.04 (0.56 to 1.91$)$ & 1.92 (0.77 to 4.52$)$ & $1.86(0.74$ to 4.4$)$ \\
\hline
\end{tabular}

${ }^{*}$ ORs adjusted for obesity $(\mathrm{BMI} \geq 30)$

tDichotomised at the 75th percentile.

$¥$ Sum of 3 PBA and DCCA.

BMI, body mass index; DCCA, 3-(2,2-dichlorovinyl)-2,2-dimethylcyclopropanecarboxylic acid; ETU, ethylenethiourea; 1-HP, 1-hydroxypyrene; 2-OH-HP, hydroxyphenanthrene; OHP,

hydroxypyrimethanil; OHT, 5-hydroxythiabendazole; 3PBA, 3-phenoxybenzoic acid; TCP, 3,5,6-trichloro-2-pyridinol.

positive association with current TCP $(\mathrm{OR}=1.75,95 \% \mathrm{CI}:(0.89$ to 3.36$)$ ), but there was no evidence of an association of current TCP with wheeze or asthma score. High levels of hydroxypyrene metabolites related to burning were not significantly associated with any respiratory outcomes.

For allergic conditions and current exposures, we found evidence of both positive and inverse associations (table 4). For occupational and residential exposures with allergic outcomes, we observed that women who currently worked in agriculture were more likely to have eczema $(\mathrm{OR}=2.54,95 \% \mathrm{CI}$ : $(1.33$ to 4.89) and itchy rash $(\mathrm{OR}=3.17,95 \% \mathrm{CI}$ : $(1.12$ to 7.73$))$, but were less likely to report rhinitis $(\mathrm{OR}=0.19,95 \% \mathrm{CI}$ : $(0.01$ to 0.93)) (table 4). Women whose partners worked in agriculture in the 3 years prior to the health survey were more likely to report an itchy rash $(\mathrm{OR}=3.44,95 \% \mathrm{CI}$ : $(1.03$ to 10.00$))$, but were less likely to report rhinitis (OR=1.04, 95\% CI: (0.16 to 3.94). Pesticide spraying by health authorities was also associated with increased rhinitis $(\mathrm{OR}=2.43,95 \% \mathrm{CI}$ : $(0.97$ to 6.93$)$ ). High exposure to OHT both historically and currently was associated with a doubling of itchy rash odds, but this was not statistically significant with either exposure (table 3 and online supplemental table S3).

Sensitivity analyses including the current and past smokers showed similar associations to those from our main models (online supplemental tables S4 and S5). Similarly, adjusting for cotinine had no effect on the results.

\section{DISCUSSION}

We used three different outcome measures to address respiratory symptoms: wheeze, asthma score (a sum of five respiratory symptoms) and doctor diagnosis of asthma. While all three have been used in epidemiologic studies, they probably measure different things in medically underserved areas than in more developed parts of the world. Health outcome data were selfreported, which is why we chose to focus more on symptoms than self-reported diagnoses where possible. Our cohort had a higher prevalence of asthma compared with other cohorts of adults. For example, AGRICOH (A Consortium of Agricultural Cohort Studies) found an average asthma prevalence of $7.8 \%$ in women in the 18 cohorts studied, while $21 \%$ of women in our cohort reported an asthma diagnosis and 37\% exhibited asthma symptoms, as measured by the asthma score. ${ }^{32}$ Our cohort did have a similar prevalence of wheeze (16\%) compared with AGRICOH, which found an average of $15 \%$ of participants had respiratory symptoms (cough and wheeze). ${ }^{32}$ A study of mothers of young children living in an urban setting in Ethiopia found a lower prevalence of wheeze (6.2\%) compared with our cohort; it also reported a statistically significant relationship between 
pesticide use in the household and respiratory symptoms. ${ }^{33} \mathrm{We}$ similarly found an association between pesticide use in the home and doctor-diagnosed asthma.

We saw little evidence of associations between current pesticide exposure measures and current respiratory symptoms and disease. A positive association between thiabendazole exposure and high asthma score was the only significant association observed for current pesticide exposures. Thiabendazole is a post-harvest fungicide, applied to bananas before packing them for export. Women working on banana plantations had higher OHT concentrations compared with women not working in agriculture. With respect to questionnaire data, the strongest association was for pesticide use in the home with an almost twofold increase in doctor-diagnosed asthma in women who reported pesticide use. We did not observe this association for asthma score or wheeze. These results suggest this association for asthma may be associated with increased use of insecticide by people with asthma, rather than insecticides leading to increased asthma risk.

OP insecticides have been associated with respiratory symptoms in other populations. ${ }^{1811}$ We found no strong evidence of an association between chlorpyrifos (measured by TCP) and respiratory symptoms. High TCP concentrations were inversely associated with wheeze, but positively associated with asthma (there was no association with asthma score). We do not have additional data to evaluate if our findings are due to chance, a difference in application methods in the study site or something else. Measurement error may have influenced these results in a number of ways. Pesticide metabolites are very short lived and only capture very recent exposures, so urinary biomarkers may miss peaks of exposure that may contribute to respiratory symptoms. This is for example reflected by the relatively low intraclass correlation coefficient of ETU during pregnancy $(\mathrm{ICC}=0.15) .{ }^{2}$ Our analysis of current exposures is cross-sectional and limited to one biomarker measurement. While the evidence was somewhat stronger for current exposures than for exposures 5 years prior, repeated measures of recent exposures would potentially help to strengthen our estimates. We attempted in our historic exposure assignment strategy to try to assign women how had been consistently highly exposed, but we probably had too few measurements to accurately assign exposure.

Frequent exposure to smoke from waste burning was associated with increased odds of a high asthma score, but not with doctor-diagnosed asthma. We did not find associations with the metabolite measurements of $\mathrm{PAH}$, which may have been due to the short half-lives of 1-HP and 2-OH-PH. While we do not have detailed data on what types of waste burning occurred, burning of residential waste can result in a diverse exposure mixture including PAHs, carbon monoxide and nitrogen oxides. ${ }^{18} 3435$ These air pollutants are known contributors to airway disease worldwide and contribute to the estimated 235 million global burden of asthma. ${ }^{17} 203637$ Given that general waste burning happens on a regular basis in this area, we expect less measurement error in the questionnaire estimates than those for $\mathrm{PAH}$ metabolites.

Although smoking is a known risk factor for respiratory disease, we excluded smokers from our main analysis due to small numbers. Our results were consistent when smokers were included or we adjusted for cotinine levels. The women in this study did not report frequent exposure to secondhand smoke in their homes. Our small sample size and the small proportion of smokers impacted our ability to examine smoking as an effect modifier.
We found less evidence for associations between pesticide metabolites and rhinitis than other studies. Our cohort had a similar prevalence of rhinitis (9\%) to a recent study in Colombia, which had a rhinitis prevalence of $10 \%$ and observed an increased risk for rhinitis in adults exposed to mixtures of paraquat, profenofos and glyphosate. ${ }^{38}$ Similarly, a study of grape farmers in Greece had a higher prevalence of allergic rhinitis (37\%) and found positive associations between use of some pesticides and allergic rhinitis. Consistent with our findings, this study did not find evidence of an association between OPs and rhinitis. ${ }^{39}$ We found that women who currently worked in agriculture were five times less likely to have rhinitis, consistent with a healthy worker effect. This finding may suggest women with rhinitis are less likely to seek employment in agriculture, or that women with rhinitis leave agricultural work. A study of occupational rhinitis in Slovakia also found a low prevalence of rhinitis in agricultural workers. ${ }^{40}$

Allergic skin conditions were more often associated with indirect measures of pesticide exposure such as agricultural work or government spraying of pesticides. Our findings were similar to research done in the United Arab Emirates (UAE) which found associations between agricultural pesticide exposures and skin conditions like eczema and itchy rash. ${ }^{15}$ A study of agricultural workers in the UAE found $21 \%$ had eczema and 24\% had rash. ${ }^{15}$ Our cohort had more eczema (31\%) than itchy rash (9\%), but both studies found associations between working in agriculture and eczema. Skin-related allergic conditions were associated with longer-term exposure (ie, both eczema and itchy rash being more common in women who currently worked in agriculture).

Additionally, high OHT concentrations were associated with increased odds of eczema and itchy rash. This finding is consistent with previous research from Panama on thiabendazole exposure and dermatologic conditions among workers in banana packing. ${ }^{41} 42$ Exposure levels of OHT were very low among most of the women in our sample and as a result the high exposed group contained women with relatively low exposures ( 75 th percentile $=0.387 \mu \mathrm{g} / \mathrm{L}, \max =299.96 \mu \mathrm{g} / \mathrm{L}$ ). These results suggest that allergic skin conditions may appear after prolonged exposure to pesticides.

Pyrethroids may contribute to allergic outcomes. Studies in Greece and the USA found associations between pyrethroid exposures and rhinitis. ${ }^{43} 44$ In our sample, women whose houses were treated for vector control were more likely to report rhinitis. Pyrethroids are commonly used for vector control in Costa Rica and around the world, both by health authorities and by individuals. In Costa Rica, pyrethroids are readily available at local markets and their sale is not regulated, therefore some women may be simultaneously exposed from personal use and vector control programmes.

The major limitation of this study is its small sample size, which restricted our statistical power. While respiratory and allergic outcomes are common, they are multifactorial outcomes, and we lacked the ability to control for other factors. We excluded women who smoked to help address that issue but that reduced our sample size further. For rhinitis, we had an even smaller sample size since some women were not asked this question. Given our small sample size, the cross-sectional nature of the majority of this analysis and the high variability in the pesticide metabolite concentrations, we still observed significant associations with these outcomes, suggesting that studies with a larger sample size with more measures of exposure are necessary to help address these questions related to pesticides and other environmental exposures and respiratory and allergic outcomes. 
Further research is needed on measures to effectively reduce pesticide exposures. For example, thiabendazole exposure primarily occurs at banana packing plants via fumigation chambers. Exposure may be mitigated through effective extraction procedures in the chambers or direct topical application rather than fumigation, but best practices in exposure reduction remain unknown. ${ }^{12}$

The ISA cohort provides a unique cohort to study the associations between environmental and occupational pesticide exposures and respiratory and allergic diseases. By studying women who experience pesticide exposure due to their living conditions and occupations we are able to explore how these exposures uniquely impact women. Our results add to the growing literature linking pesticides and disease among women.

\section{Author affiliations}

'Duke Clinical Research Institute, Duke University, Durham, North Carolina, USA ${ }^{2}$ Center for Human Health and the Environment, North Carolina State University, Raleigh, North Carolina, USA

${ }^{3}$ Infants' Environmental Health (ISA) Study, Central American Institute for Studies on Toxic Substances (IRET), Universidad Nacional de Costa Rica, Heredia, Costa Rica ${ }^{4}$ Respiratory Department, Hospital Nacional de Niños, San Jose, Costa Rica ${ }^{5}$ Center for Environmental Research and Children's Health (CERCH), University of California Berkeley, Berkeley, California, USA

${ }^{6}$ Department of Statistics, North Carolina State University, Raleigh, North Carolina, USA

${ }^{7}$ Division of Occupational and Environmental Medicine, Institute of Laboratory Medicine, Lund University, Lund, Sweden

${ }^{8}$ Department of Biological Sciences, North Carolina State University, Raleigh, NC, USA

Acknowledgements We gratefully acknowledge the ISA families, staff and community partners. We would also like to thank Michael Cuffney, Juan Camilo Cano, Rosario Quesada, Claudia Hernandez, Diego Hidalgo, Jorge Peñaloza Castañeda, Alighierie Fajardo Soto, Marie Bengtsson, Daniela Pineda, Moosa Faniband and Margareta Maxe for their fieldwork, laboratory analyses and/or data management assistance.

Contributors JAH and BvWdJ wrote the grant for this project, developed study materials, conducted field research, supervised data collection and analysis and contributed to the writing and final review of the manuscript. BA conducted the statistical analyses, drafted the manuscript and finalised the manuscript for publication. MS-M provided expertise on pulmonology, reviewed study materials, provided comments on the initial and final drafts of the manuscript. AMM helped in the development of study materials, provided input during data collection and reviewed draft and final versions of the manuscript. LCG and MQ-L collected all data in the field, provided input on study protocols and reviewed draft and final versions of the manuscript. BR provided input on the statistical analysis of the data and reviewed and commented on draft and final versions of the manuscript. CHL helped develop the grant, provided input on study design, conducted chemical analyses of urine samples and reviewed draft and final versions of the manuscript. JAH accepts full responsibility for the work and conduct of the study, had access to the data, and controlled the decision to publish.

Funding This publication was made possible by research supported by grant numbers: P01 105296-001 (IDRC); 6807-05-2011/7300127 (Health Canada); 2010-1211, 2009-2070 and 2014-01095 (Swedish Research Council Formas); R21 ES025374 (NIEHS) and R24 ES028526 (NIEHS).

Competing interests None declared.

Patient consent for publication Not applicable.

Ethics approval This study involves human participants and was approved by the ethical and scientific committee of the Universidad Nacional in Costa Rica (UNACECUNA-ACUE-32-2018). Participants gave informed consent to participate in the study before taking part.

Provenance and peer review Not commissioned; externally peer reviewed.

Data availability statement No data are available. Deidentified participant data are stored in a secure server by the ISA study team. Please contact the research team for interest in potential data access.

Supplemental material This content has been supplied by the author(s). It has not been vetted by BMJ Publishing Group Limited (BMJ) and may not have been peer-reviewed. Any opinions or recommendations discussed are solely those of the author(s) and are not endorsed by BMJ. BMJ disclaims all liability and responsibility arising from any reliance placed on the content. Where the content includes any translated material, BMJ does not warrant the accuracy and reliability of the translations (including but not limited to local regulations, clinical guidelines, terminology, drug names and drug dosages), and is not responsible for any error and/or omissions arising from translation and adaptation or otherwise

Open access This is an open access article distributed in accordance with the Creative Commons Attribution Non Commercial (CC BY-NC 4.0) license, which permits others to distribute, remix, adapt, build upon this work non-commercially, and license their derivative works on different terms, provided the original work is properly cited, appropriate credit is given, any changes made indicated, and the use is non-commercial. See: http://creativecommons.org/licenses/by-nc/4.0/.

\section{ORCID iDs}

Brooke Alhanti http://orcid.org/0000-0003-4243-8062

Berna van Wendel de Joode http://orcid.org/0000-0001-9699-5046

Manuel Soto Martinez http://orcid.org/0000-0002-5509-6164

Ana M Mora http://orcid.org/0000-0002-2008-9714

Christian H Lindh http://orcid.org/0000-0001-7435-9890

Jane A Hoppin http://orcid.org/0000-0001-8456-0969

\section{REFERENCES}

1 Fieten $\mathrm{KB}$, Kromhout $\mathrm{H}$, Heederik $\mathrm{D}$, et al. Pesticide exposure and respiratory health of Indigenous women in Costa Rica. Am J Epidemiol 2009;169:1500-6.

2 van Wendel de Joode B, Mora AM, Córdoba L. Aerial application of mancozeb and urinary ethylene thiourea (ETU) concentrations among pregnant women in Costa Rica: The infants' environmental health study (ISA). Environ Health Perspect 2015.

3 van Wendel de Joode B, Barraza D, Ruepert C, et al. Indigenous children living nearby plantations with chlorpyrifos-treated bags have elevated 3,5,6-trichloro-2-pyridinol (TCPy) urinary concentrations. Environ Res 2012;117:17-26.

4 National Institute of Statistics and Censuses (Costa Rica). Costa Rica National Household Survey. San José, Costa Rica: National Institute of Statistics and Censuses (Costa Rica), 2019.

5 Park E, Lee K. Particulate exposure and size distribution from wood burning stoves in Costa Rica. Indoor Air 2003;13:253-9.

6 Barraza D, Jansen $\mathrm{K}$, van Wendel de Joode B, et al. Pesticide use in banana and plantain production and risk perception among local actors in Talamanca, Costa Rica. Environ Res 2011:111:708-17.

7 Hoppin JA, Umbach DM, London SJ, et al. Pesticides associated with wheeze among commercial pesticide applicators in the agricultural health study. Am J Epidemiol 2006:163:1129-37.

8 Hoppin JA, Umbach DM, London SJ, et al. Pesticides and atopic and nonatopic asthma among farm women in the agricultural health study. Am J Respir Crit Care Med 2008; 177:11-18

9 Nigatu AW, Bråtveit M, Deressa W, et al. Respiratory symptoms, fractional exhaled nitric oxide \& endotoxin exposure among female flower farm workers in Ethiopia. J Occup Med Toxicol 2015:10:8.

10 García AM. Pesticide exposure and women's health. Am J Ind Med 2003;44:584-94.

11 Ndlovu V, Dalvie MA, Jeebhay MF. Asthma associated with pesticide exposure among women in rural Western Cape of South Africa. Am J Ind Med 2014;57:1331-43.

12 Mora Fallas M. Exposición de madres Y Sus hijos al fungicida tiabendazol en El cantón de Matina. Csita Rica: resultados del infantes y salud ambiental (ISA), 2017. http:// www.isa.una.ac.cr/images/articulos/tesis/2017_Tesis_Marcela_Mora_Fallas.pdf

13 Negatu B, Kromhout H, Mekonnen Y, et al. Occupational pesticide exposure and respiratory health: a large-scale cross-sectional study in three commercial farming systems in Ethiopia. Thorax 2017;72:498.1-9.

14 Gangemi S, Miozzi E, Teodoro M, et al. Occupational exposure to pesticides as a possible risk factor for the development of chronic diseases in humans (Review). Mol Med Rep 2016;14:4475-88

15 Beshwari MMM, Bener A, Ameen A, et al. Pesticide-related health problems and diseases among farmers in the United Arab Emirates. Int J Environ Health Res 1999:9:213-21.

16 Buralli RJ, Dultra AF, Ribeiro H. Respiratory and allergic effects in children exposed to Pesticides-A systematic review. Int I Environ Res Public Health 2020;17:2740.

17 Kurmi OP, Lam KBH, Ayres JG. Indoor air pollution and the lung in low- and mediumincome countries. Eur Respir J 2012;40:239-54.

18 Pongpiachan S, Hattayanon M, Cao J. Effect of agricultural waste burning season on PM2.5-bound polycyclic aromatic hydrocarbon (PAH) levels in northern Thailand. Atmos Pollut Res 2017.

19 Roy B, Goh N. A review on smoke haze in Southeast Asia: deadly impact on health and economy. Quest Int J Med Heal Sci 2019

20 Sanhueza PA, Torreblanca MA, Diaz-Robles LA, et al. Particulate air pollution and health effects for cardiovascular and respiratory causes in Temuco, Chile: a woodsmoke-polluted urban area. J Air Waste Manag Assoc 2009;59:1481-8.

21 Mora AM, Hoppin JA, Córdoba L, et al. Prenatal pesticide exposure and respiratory health outcomes in the first year of life: results from the infants' environmental health (Isa) study. Int J Hyg Environ Health 2020;225:113474. 
22 Burney PG, Luczynska C, Chinn S, et al. The European community respiratory health survey. Eur Respir J 1994;7:954-60.

23 Gascon M, Kromhout H, Heederik D, et al. Respiratory, allergy and eye problems in bagasse-exposed sugar cane workers in Costa Rica. Occup Environ Med 2012;69:331-8.

24 Rodríguez-Zamora MG, Zock J-P, van Wendel de Joode B, et al. Respiratory health outcomes, rhinitis, and eczema in workers from grain storage facilities in Costa Rica. Ann Work Expo Health 2018;62:1077-86.

25 Sunyer J, Pekkanen J, Garcia-Esteban R, et al. Asthma score: predictive ability and risk factors. Allergy 2007;62:142-8.

26 Jarvis D, European Community Respiratory Health Survey II Steering Committee. The European community respiratory health survey II. Eur Respir J 2002:20:1071-9.

27 Hoppin JA, Jaramillo R, Salo P, et al. Questionnaire predictors of atopy in a US population sample: findings from the National health and nutrition examination survey, 2005-2006. Am J Epidemiol 2011;173:544-52.

28 Norén $\mathrm{E}$, Lindh $\mathrm{C}$, Rylander $\mathrm{L}$, et al. Concentrations and temporal trends in pesticide biomarkers in urine of Swedish adolescents, 2000-2017. J Expo Sci Environ Epidemiol 2020:30:756-67.

29 Jeng HA, Pan CH. 1-Hydroxypyrene as a biomarker for environmental health. In: General methods in biomarker research and their applications, 2015.

30 Alhamdow A, Lindh C, Albin M, et al. Early markers of cardiovascular disease are associated with occupational exposure to polycyclic aromatic hydrocarbons. Sci Rep 2017; 7:9426.

31 R Core Team. R: a language and environment for statistical computing. Vienna, Austria, 2019.

32 Fix J, Annesi-Maesano I, Baldi I, et al. Gender differences in respiratory health outcomes among farming cohorts around the globe: findings from the AGRICOH Consortium. J Agromedicine 2021;26:97-108.
33 Andualem Z, Azene ZN, Azanaw J, et al. Acute respiratory symptoms and its associated factors among mothers who have under five-years-old children in northwest, Ethiopia. Environ Health Prev Med 2020;25:20.

34 Crutzen PJ, Andreae MO. Biomass burning in the tropics: impact on atmospheric chemistry and biogeochemical cycles. Science 1990;250:1669-78.

35 Huang $\mathrm{Y}$, Shen $\mathrm{H}$, Chen $\mathrm{Y}$, et al. Global organic carbon emissions from primary sources from 1960 to 2009. Atmos Environ 2015;122:505-12.

36 Ferkol T, Schraufnagel D. The global burden of respiratory disease. Ann Am Thorac Soc 2014;11:404-6.

37 Låg M, Øvrevik J, Refsnes M, et al. Potential role of polycyclic aromatic hydrocarbons in air pollution-induced non-malignant respiratory diseases. Respir Res 2020;21:299.

38 Díaz-Criollo S, Palma M, Monroy-García AA, et al. Chronic pesticide mixture exposure including paraquat and respiratory outcomes among Colombian farmers. Ind Health 2020;58:15-21.

39 Chatzi L, Alegakis A, Tzanakis N, et al. Association of allergic rhinitis with pesticide use among grape farmers in Crete, Greece. Occup Environ Med 2007;64:417-21.

40 Perečinský S, Legáth L'ubomír, Varga M, et al. Occupational rhinitis in the Slovak Republic--a long-term retrospective study. Cent Eur J Public Health 2014;22:257-61.

41 Penagos HG. Contact dermatitis caused by pesticides among banana plantation workers in Panama. Int J Occup Environ Health 2002;8:14-18.

42 Penagos H, Ruepert C, Partanen T, et al. Pesticide patch test series for the assessment of allergic contact dermatitis among banana plantation workers in Panama. Dermatitis 2004;15:137.

43 Slager RE, Simpson SL, Levan TD, et al. Rhinitis associated with pesticide use among private pesticide applicators in the agricultural health study. J Toxicol Environ Health $A$ 2010;73:1382-93.

44 Koureas M, Rachiotis G, Tsakalof A, et al. Increased frequency of rheumatoid arthritis and allergic rhinitis among pesticide sprayers and associations with pesticide use. Int Environ Res Public Health 2017;14:865. 